\title{
Users Perspectives on Online Pharmacy Model
}

\author{
Architha Aithal $^{1}$ \& Dr. A. R. Shabaraya ${ }^{2}$ \\ ${ }^{1}$ Third Year Pharma D., Srinivas College of Pharmacy, Valachil, Mangalore, INDIA \\ E-mail: aithalarchitha@gmail.com \\ ${ }^{2}$ Director, Srinivas College of Pharmacy, Valachil, Mangalore - 575 001, INDIA \\ E-mail : shabaraya1@gmail.com
}

Type of the Paper: Research Article.

Type of Review: Peer Reviewed.

Indexed In: OpenAIRE.

DOI: http://dx.doi.org/10.5281/zenodo.1292790.

Google Scholar Citation: IJHSP

\section{How to Cite this Paper:}

Architha Aithal., Shabaraya, A. R. (2018). Users Perspectives on Online Pharmacy Model. International Journal of Health Sciences and Pharmacy (IJHSP), 2(1), 29-36. DOI: http://dx.doi.org/10.5281/zenodo.1292790.

International Journal of Health Sciences and Pharmacy (IJHSP)

A Refereed International Journal of Srinivas University, India.

(C) With Authors.

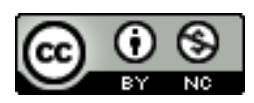

This work is licensed under a Creative Commons Attribution-Non Commercial 4.0 International License subject to proper citation to the publication source of the work.

Disclaimer: The scholarly papers as reviewed and published by the Srinivas Publications (S.P.), India are the views and opinions of their respective authors and are not the views or opinions of the SP. The SP disclaims of any harm or loss caused due to the published content to any party. 


\title{
Users Perspectives on Online Pharmacy Model
}

\author{
Architha Aithal $^{1}$ \& Dr. A. R. Shabaraya ${ }^{2}$ \\ ${ }^{1}$ Third Year Pharma D., Srinivas College of Pharmacy, Valachil, Mangalore, INDIA \\ E-mail : aithalarchitha@gmail.com \\ ${ }^{2}$ Director, Srinivas College of Pharmacy, Valachil, Mangalore - 575 001, INDIA \\ E-mail : shabaraya1@gmail.com
}

\begin{abstract}
The advents in technology through continuous innovations have supported to improve the quality of the human life in the society. One of the innovation due to the invention of ICT based online/mobile high-speed internet is e-business which allowed the development of online shopping/purchase of both intangible and tangible commodities online. The major advantage and benefit of this online model is its ubiquity, convenience, and low cost to the customer. The online shopping/purchase model is now becoming popular especially among youngsters. One variation of this e-purchase model is online pharmacy model where a consumer can purchase the prescribed drug online to take some of the advantages of this model. In this paper, we have studied the customer's attitude, views, and concern on this new channel of drug distribution using the data collected by online questionnaire from the general population. The data obtained from this survey is analysed, assessed and interpreted. Based on information collected and focused group study, the online pharmacy model is analysed using $A B C D$ analysis framework. The various issues related to online pharmacy, affecting factors are studies under ABCD constructs using ABCD listing methodology. Based on the outcome of the study, many recommendations are suggested for developing proper controlling mechanism/regulations for drug control authorities of the country to avoid misuse of the online channel for the drug purchase.
\end{abstract}

Keywords: Online pharmacy, Online Drug Purchase, E-Pharmacy, Online pharmacy regulations, ABCD listing of online pharmacy, Online dispensing, Customer satisfaction, Drug abuse.

\section{INTRODUCTION :}

The rapid increase in high-speed internet usage at low cost using mobile devices ubiquitously (anytime anywhere any amount of time) has promoted the online purchase of various tangible and intangible commodities. Though online purchase of intangible commodities using mobile internet devices is an example of an ideal business model, purchase of tangible commodities online has its own constraints [1]-[2]. The major limitations are transportation time and reliability on quality of products. But the advantages and benefits of online purchase of commodities have surpassed compared to constraints and disadvantages. Online purchase is gaining popularity nowadays, for example, many commodities like electronic goods, books, household commodities etc. due to the reason of increased choice, enhanced discount, free and cash on delivery, and assured return kind of attributes in present online model. This created a big change in the perception of people in online purchase model of commodities and gained accelerated speed of usage by major customers irrespective of their gender, age, education background, and location. Based on enhanced demand for online shopping, more vendors are started/shifted to online sales business model and tried to encash the opportunities in this business area. However, in some of the industries, due to peculiar nature of the products/services/ or security reasons or Government regulations cannot support this 
online sales model. For example, flower industry, vegetable industry, fire-cracker industry, pharmaceutical industry etc. where the purchase of products depends on various additional attributes like time, odour, freshness, or genuine prescriptions etc. However, this increase in the sales of online consumer goods may comprise the inclusion of the sales of online drugs as well. Online pharmacies as the name suggests are pharmacies that are operational over the Internet and seek to provide its customers with options to buy medicines online. It provides the incentives to the people suffering from health conditions to help them manage their medicines with nominal effort. With the advent of the Internet, the gap between people living in rural areas and leading medical facilities of the country has also reduced to a bare minimal and online purchase of medicines assures the supply within some predetermined fixed time [3]-[9]. As beneficial as this new technology has been to its users, the risks involved in purchasing pharmaceutical products online cannot be shelved. The functionality and legality of e-Pharmacies have been questioned in present time in India, nationally as well as internationally. In the year 2008, World Health Organization (WHO) issued a contemptuous disparagement to the Indian drug regulatory system by raising strong objections to India's drug approval mechanism, which according to it are, "....approved in the country without proper documentation on pre-clinical, clinical and toxicological studies." WHO further observed that the "Indian drug regulatory authority is not independent and is functioning under pressure." Such observations have belittled the internationally established reputation of the country, which by volume is the fourth largest pharmaceutical market in the world. As a result, the safety of the patients/consumers who use online drugs is in question and the dilemma of using such unsecured channel for drug dispensing is the present concern for many regulatory bodies.

\section{NEED FOR STUDY :}

Online sales and purchase of various commodities are increasing in both developed and developing countries due to the accessibility of ubiquitous internet and awareness. For the reason of accessibility of information communication technology at considerably low cost, availability of improved supply chain for online purchase of commodities there is an increased interest among various category of people, there are concerns and curiosity on purchasing and selling of medicines online. Many online medicine suppliers have already started selling and marketing their products by demonstrating through websites and offering 35\% to 55\% discounts to customers [10]-[15].

\section{OBJECTIVES :}

- To study the knowledge and perception of general population about the online pharmacies.

- To analyze the advantages, benefits, constraints, and disadvantages of online pharmacy.

- To suggest changes required in drug regulation acts in India by considering the regulatory requirements for the online pharmacy.

- To analyse Threats /Opportunities for pharmacists in Online Pharmacy Model.

\section{MATERIALS AND METHODS :}

Empirical survey research method is used to study customer attitude and behaviour towards online pharmacy medicine purchase model. The convenient sample of size 258 is obtained through the online questionnaire with inclusion criteria of the general population who are above 18 years old. For review and discussion, articles were collected from the online sources such as PUBMED, WHO, FDA and GOOGLE SCHOLAR and questionnaires were prepared by using these articles. The data obtained from this survey is analysed, assessed and interpreted. Based on information collected and focused group study, the online pharmacy model is analysed using ABCD analysis framework. The various issues related to online pharmacy, affecting factors are studies under ABCD constructs. The critical constituent elements of the advantages, benefits, constraints, and disadvantages are identified. Based on the outcome of the study, many recommendations are suggested for developing proper controlling mechanism/regulations for drug control authorities of the country to avoid misuse of 
the online channel for the drug purchase [16][17].

\section{RESULTS AND DISCUSSION}

\subsection{Analysis of Data :}

A total of 258 responses were collected and analysed from our survey. Among them, 12 respondents were studying or working in commerce and business sector; 63 respondents were studying or working in technology sector; 113 respondents were studying or working in healthcare sector; and remaining were housewives or retired people. The results are depicted in the following figures.

Table 1: Occupation of Respondents

\begin{tabular}{|l|l|c|c|}
\hline S. No. & Occupation & Frequency & Percentage \\
\hline 1 & Student - health science sector & 105 & 41 \\
\hline 2 & Working - health science sector & 47 & 18 \\
\hline 3 & Student - technology sector & 10 & 4 \\
\hline 4 & Working - technology sector & 8 & 3 \\
\hline 5 & Student - commerce and business sector & 57 & 22 \\
\hline 6 & Working - commerce and business sector & 31 & 12 \\
\hline
\end{tabular}

From the above table 1 , it is clear that $41 \%$ of the sample respondents are health science sector students.

Table 2 : The mode of purchase

\begin{tabular}{|l|l|c|c|}
\hline S. No. & Mode of the purchase & Frequency & Percentage \\
\hline 1 & Always from Offline & 235 & 91 \\
\hline 2 & Always from Online & 5 & 2 \\
\hline 3 & Both online/offline & 18 & 7 \\
\hline
\end{tabular}

From the above table 2, it is clear that $91 \%$ of the sample respondents purchase medicine always from offline.

Table 3 : Consideration of Online pharmacy purchase model

\begin{tabular}{|l|l|c|c|}
\hline S. No. & Consideration by Respondents & Frequency & Percentage \\
\hline 1 & Yes, Have used one before/am using one now & 18 & 7 \\
\hline 2 & Have considered it, but never used one & 85 & 33 \\
\hline 3 & No & 155 & 60 \\
\hline
\end{tabular}

From table 3, it is clear that $60 \%$ of the sample respondents have not considered online purchase of medicine.

Table 4 : Reason for not Considering Online pharmacy purchase model

\begin{tabular}{|l|l|c|c|}
\hline S. No. & Reasons for not Considering Online & Frequency & Percentage \\
\hline 1 & Do not trust quality & 108 & 42 \\
\hline 2 & Not aware that they exist & 28 & 11 \\
\hline 3 & Happy with current arrangement & 119 & 46 \\
\hline 4 & Do not have easy access to internet & 3 & 1 \\
\hline
\end{tabular}

From table 4 , it is clear that $46 \%$ of the sample respondents are happy with offline purchase of medicine. 
Table 5 : Factors attracted to the respondents to buy medications online

\begin{tabular}{|l|l|c|c|}
\hline S. No. & Factors of Attraction & Frequency & Percentage \\
\hline 1 & Choice of delivery time and address & 62 & 18.56 \\
\hline 2 & Reduces visits to Pharmacy & 90 & 26.94 \\
\hline 3 & Attractive discounts on prices and offers & 109 & 32.63 \\
\hline 4 & Freedom to choose any brand of drugs of a given generic name & 49 & 14.67 \\
\hline 5 & Sometimes they sell drugs without prescription & 24 & 7.18 \\
\hline
\end{tabular}

From table 5, it is clear that $32.63 \%$ of the sample respondents who also purchase medicines online feel that attractive discounts on prices and offers are major factor for their decision.

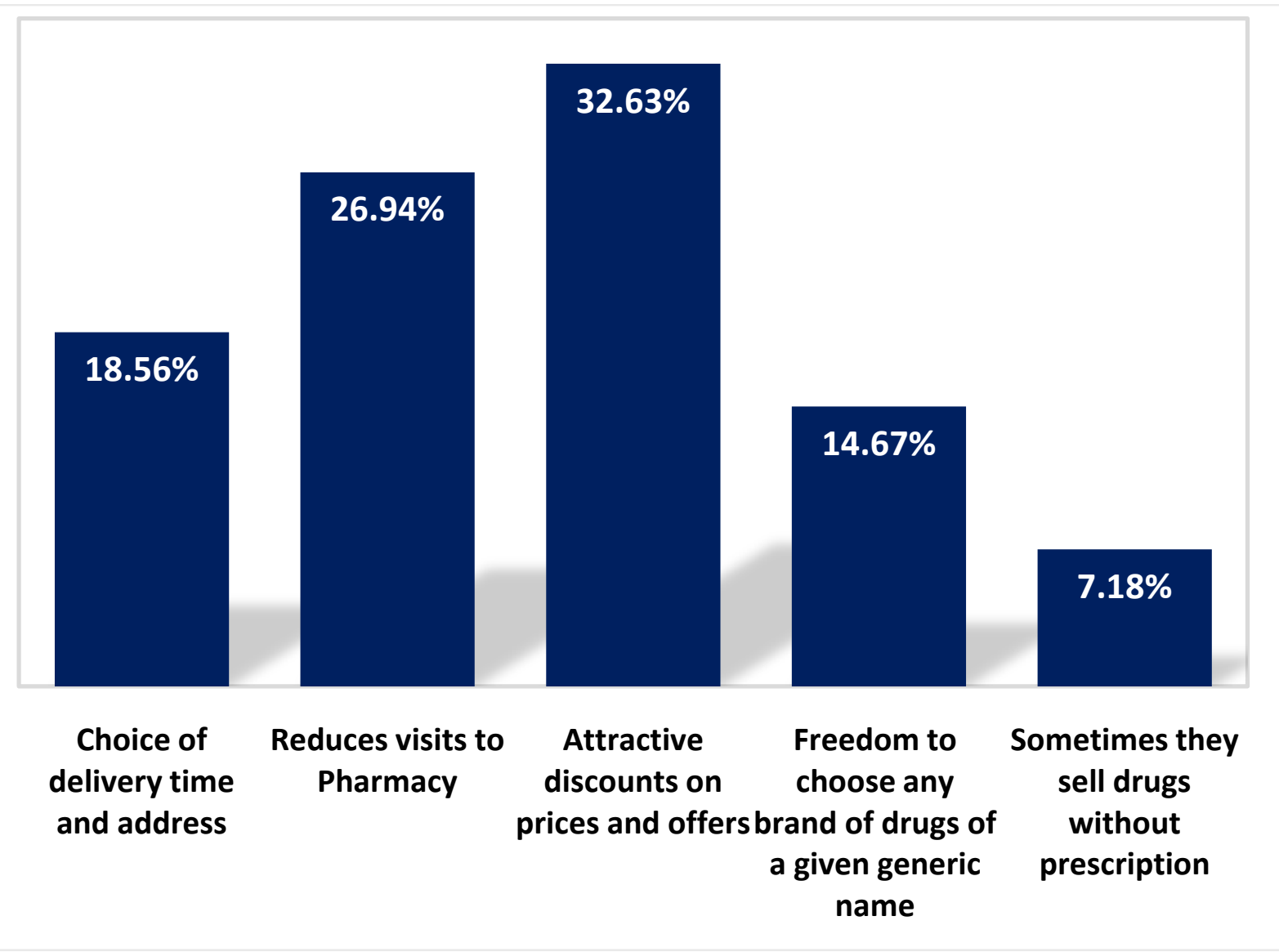

Fig. 1: Factors which attract the customer to buy medications

\section{ABCD LISTING AND ANALYSIS OF} ONLINE PHARMACY :

The concept of online pharmacy can be analysed using ABCD framework [18]-[20]. ABCD framework is divided into two parts as (i) ABCD listing and (ii) ABCD analysis which are qualitative and quantitative aspects of the framework.

\subsection{Advantages:}

- Easy access to healthcare

- Any time order placement
- Privacy on purchase of drugs

- Discounts and offers on prices

- Freedom to choose from many brands

- Choice of delivery time and address

- Free delivery and Cash on delivery of ordered drugs

- For differently abled and elderlies

- Secured customer information through IP tracking \& Address proof

- Avoiding the middleman/ retailer in the sales chain. 


\subsection{Benefits:}

- Cheaper healthcare

- Customer convenience

- Competition based low cost

- Time saving on pharmacy visit

- Nondisclosure of medical conditions of individuals

- Avoiding of Travel and Waiting period in offline pharmacy purchase

- Control of illegal drug delivery and usage

- Better quality drugs due to choice of many brands

- Reduces the visits to pharmacy

6.3 Constraints:

- Emergency delivery of medicine

- Requirement of Internet facility

- Smart phone / computer for order placement

- Damaged goods supply

- Difficulty in maintenance of quality/freshness /potency during transportation

- Difficulty in verifying the authenticity of prescriptions

- Lack of regulation in online pharmacy

6.4 Disadvantages:

- Self-medication

- Lack of patient counseling

- Counterfeit / fake/ outdated medicines

- Unavailability of online services in many places

- Non-reliability on shipping services

- Exchange and return of drugs (depending on model)

It can be argued that advantages and benefits are surpassing the constraints and disadvantages for a responsible and genuine customer for using inline pharmacy as an additional channel of drug purchase like the online purchase of any other commodity. The ubiquitous nature of this model provided by the advent of information communication technology supported through high speed internet services along with the main benefits of cost savings and enhanced choice option availing at our doorsteps is definitely a plus and hence online purchase of drugs at least for chronic deceases are going to be a boon provided the legal aspects of drug misuse by all stakeholders is taken care. As per ABCD listing, it is also argued that the online purchase channel of medicines is an additional facility but not a substitution for pharmacy dispensing and not a threat to pharmacy professionals.

\section{LEGAL MECHANISMS IN FORCE IN INDIA :}

The present Law doesn't identify online advertisement or trade of drugs, though there are measures to check the authenticity of drug ingredients or finished formulations when they are physically transferred from one place to another. There are no well-defined dedicated laws for online pharmacies. The fast and uncontrollably growing number of online pharmacies has posed a serious challenge to the State Drug Control Authorities. In the absence of strictly dedicated laws, Indian pharmacies are relying majorly on the Information Technology Act, 2000, the Drug and Cosmetics Act, 1940, the Drugs and Cosmetics Rules, 1945 and the Pharmacy Act, 1948 which all are old and outdated for online business models [21]. Further, Section 10 of the Drugs and Cosmetics Act, 1940 prohibits the import of certain drugs or cosmetics, which are not of standard quality, misbranded, adulterated etc. However, if an illegal pharmacist is selling medicines online, the Drugs and Cosmetics Act, 1940 does not enumerate how the quality or standard of such medicines shall be ensured. There is a need of amendments for the existing acts regards to collectively governing sale and purchase of prescribed drugs and medicines online [22].

\section{ROLE OF CONSUMERS :}

Consumer awareness is the key to curb such fraudulent practices; consumers need to be educated about the need to verify the authenticity of the service provider as well as the product and to avoid sites that sell drugs without a legal prescription. Good online pharmacies have well-defined safety and quality benchmarks, uncomplicated privacy and security policies, a verifiable physical address and licensed pharmacist on the roll. Clinicians should familiarize themselves with a few reputable and legitimate online pharmacies that they may recommend to their patients. 


\section{SUGGESTIONS :}

(1) Restrictions should be imposed on online Pharmacy service providers to make use of qualified pharmacists at dispensing of ordered drugs.

(2) Purchase of scheduled $\mathrm{H}$ or scheduled $\mathrm{X}$ drugs should be periodically tracked for avoiding misuse.

(3) A digital prescription instead of scanned or photo form will avoid in submitting fake prescriptions.

(4) An awareness of online purchase of medicines for the patient by the Govt. is necessary for better patient management and avoidance of the consequences of selfmedication.

(5) The adequate monitoring from regulators can help the consumer reap rich benefits of online pharmacies, by avoiding the inherent risks involved.

\section{CONCLUSION :}

Online selling of medicines seems to have an equal number of pros and cons. Since we lack regulations as of now, there is more inclination towards cons. We also know that making regulations in India is one thing and ensuring their strict implementation is another. There will always be a fear of fraudulence even if online pharmacists get the nod from the government. If rules are actually made to be strictly followed, the other side of the coin looks very promising. Imagine how easier it would be for remote areas to have access to all sorts of medicines that might not be easily available on their local pharmacy stores. Having faith in FDI and health ministry to make proper regulations before showing green signals to e-pharmacists, we can hope for cheaper and convenient healthcare at our doorstep.

\section{REFERNCES :}

[1] Richard, M. O., Chebat, J. C., Yang, Z., \& Putrevu, S. (2010). A proposed model of online consumer behavior: Assessing the role of gender. Journal of Business Research, 63(9-10), 926-934.

[2] Aithal, P. S. (2016). A Review on various E-business and M-business models \& Research Opportunities, International Journal of Management, IT and Engineering (IJMIE), 6(1), 275-298, DOI : http://doi.org/10.5281/zenodo.161146.

[3] Fan, G. E. N. G., \& Ying, B. I. A. N. (2008). Development of B to C Ecommerce in Pharmaceutical Industry and the Strategy for the Development of Ecommerce in China's Pharmaceutical Retail Chains [J]. China Pharmacy, 4, 036.

[4] Wiedmann, K. P., Hennigs, N., Pankalla, L., Kassubek, M., Seegebarth, B., \& Reeh, M. O. (2010). Online distribution of pharmaceuticals: investigating relations of consumers' value perception, online shopping attitudes and behaviour in an epharmacy context. Journal of Customer Behaviour, 9(2), 175-199.

[5] Crawford, S. Y. (2003). Internet pharmacy: issues of access, quality, costs, and regulation. Journal of Medical Systems, 27(1), 57-65.

[6] Gallagher, J. C., \& Colaizzi, J. L. (2000). Issues in Internet pharmacy practice. Annals of Pharmacotherapy, 34(12), 1483-1485.

[7] Bernath, P. (2003). Regulation of online pharmacy: an Australian perspective. Journal of law and medicine, 10(3), 339-363.

[8] Alwon, B. M., Solomon, G., Hussain, F., \& Wright, D. J. (2015). A detailed analysis of online pharmacy characteristics to inform safe usage by patients. International journal of clinical pharmacy, 37(1), 148-158.

[9] Fittler, A., Lankó, E., Brachmann, B., \& Botz, L. (2013). Behaviour analysis of patients who purchase medicines on the internet: can hospital pharmacists facilitate online medication safety?. European Journal of Hospital Pharmacy: Science and Practice, 20(1), 8-12.

[10] Desai, C. (2016). Online pharmacies: A boon or bane?. Indian journal of pharmacology, 48(6), 615-616.

[11] Bessell, T. L., Anderson, J. N., Silagy, C. A., Sansom, L. N., \& Hiller, J. E. (2003). Surfing, self-medicating and safety: buying non-prescription and complementary medicines via the internet. BMJ Quality \& Safety, 12(2), 88-92.

[12] Bessell, T. L., Silagy, C. A., Anderson, J. N., Hiller, J. E., \& Sansom, L. N. (2002). 
Quality of global e-pharmacies: can we safeguard consumers?. European journal of clinical pharmacology, 58(9), 567-572.

[13] Wiedmann, K. P., Hennigs, N., Pankalla, L., Kassubek, M., Seegebarth, B., \& Reeh, M. O. (2010). Online distribution of pharmaceuticals: investigating relations of consumers' value perception, online shopping attitudes and behaviour in an epharmacy context. Journal of Customer Behaviour, 9(2), 175-199.

[14] Walsh, P. J. (2000). E-pharmacy systems. Prescription and medication fulfillment come of age. MD computing: computers in medical practice, 17(3), 45-48.

[15] Gagnon, J. P. (2000, October). EPharmacy: fundamentals of e-business and implications for pharmacy service. Academy of Managed Care PharmacyEducational Conference. San Diego, California: Managed Care Primer.

[16] Zeman, S. E. (2001). Regulation of online pharmacies: A case for cooperative federalism. Annals Health L., 10, 105.

[17] Oliver, A. J. (2000). Internet pharmacies: regulation of a growing industry. The Journal of Law, Medicine \& Ethics, 28(1), 98-101.

[18] Aithal, P. S., Shailashree, V. T., Suresh Kumar, P. M. (2015). A New ABCD Technique to Analyze Business Models \& Concepts, International Journal of Management, IT and Engineering (IJMIE), 5(4), 409-423. DOI :http://doi.org/10.52 81/zenodo.61652.

[19] Aithal, P. S. (2016). Study on ABCD Analysis Technique for Business Models, Business strategies, Operating Concepts \& Business Systems, International Journal in Management and Social Science, 4(1), 98-115. DOI : http://doi.org/10.5281/zenodo.161137.

[20] Architha Aithal, and Aithal, P. S., (2017). ABCD Analysis of Task Shifting - An optimum Alternative Solution to Professional Healthcare Personnel Shortage. International Journal of Health Sciences and Pharmacy (IJHSP), 1(2), 36-51. DOI: http://dx.doi.org/ 10.5281/zenodo.1038975.
[21] Ramesh Bhat (1996). Regulating the private health care sector: the case of the Indian Consumer Protection Act. Health Policy and Planning, 11(3), 265-279. DOI https://doi.org/10.1093/heapol/11.3.265.

[22] Montoya, I. D., \& Jano, E. (2007). Online pharmacies: safety and regulatory considerations. International Journal of Health Services, 37(2), 279-289. 